\title{
IMPLANTAÇÃO DO TESTE DA LINGUINHA NO NUTEP
}

LOPES, J.S.M. ${ }^{1}$

${ }^{1}$ Fonoaudióloga e Supervisora do Setor de Fonoaudiologia do Núcleo de Tratamento e Estimulação Precoce/UFC; Especialista em Desenvolvimento Infantil e no Conceito Neuroevolutivo Bobath. E-mail: jovankasml@ hotmail.com

Artigo submetido em 17/03/2018

\section{RESUMO}

O Teste da Linguinha proporciona a triagem, avaliação e diagnóstico precoce do frênulo lingual em bebês, visando promover o desenvolvimento eficaz das funções orofaciais, especialmente a sucção e deglutição. O objetivo deste estudo foi relatar a implantação do Teste da Linguinha no Setor de Fonoaudiologia do Núcleo de Tratamento e Estimulação Precoce - NUTEP, enquanto uma atividade extensionista que busca a promoção da saúde, a qualidade de vida junto às crianças assistidas na instituição e àquelas referenciadas pela Rede Municipal de Saúde da Prefeitura de Fortaleza, bem como a capacitação profissional dos envolvidos. O teste foi aplicado em 286 crianças. Em $76(27 \%)$ crianças o frênulo lingual foi normal, em $35(12 \%)$ duvidoso e em $175(61 \%)$ alterado. A cirurgia foi realizada em 12 (7\%) crianças, enquanto $163(93 \%)$ aguardam a cirurgia, o que revela uma deficiência na assistência a estas crianças.

PALAVRAS-CHAVE: Freio lingual. Protocolos Clínicos. Aleitamento Materno. Triagem Neonatal.

\section{IMPLANTATION THE LITTLE TONGUE'S TEST IN NUTEP}

\begin{abstract}
The Little Tongue's Test provides the screening, evaluation and early diagnosis of the lingual frenulum in infants, aiming to promote the effective development of orofacial functions, especially sucking and swallowing. The objective of this study was to report the implantation of the Little Tongue's Test in the NUTEP's Speech Therapy Sector, as an extensionist activity that seeks to promote health, quality of life of the children assisted in the institution
\end{abstract}

\begin{abstract}
and those referenced by the referred by the Health Department of Fortaleza's City Hall, as well as the professional training of those involved. The test was applied to 286 children. In $76(27 \%)$ children the lingual frenulum was normal, in $35(12 \%)$ doubtful and in $175(61 \%)$ altered. Surgery was performed in $12(7 \%)$ children, while $163(93 \%)$ await surgery, which revealed a deficiency in the care of these children.
\end{abstract}

KEYWORDS: Lingual Frenum. Clinical Protocols. Breast Feeding. Neonatal Screening.

\section{INTRODUÇÃO}

A Extensão Universitária é o processo educativo, cultural e científico que articula o Ensino e a Pesquisa de forma indissociável e viabiliza a relação transformadora entre Universidade e Sociedade (FORUM..., 2006, p. 21).

No âmbito da Universidade Federal do Ceará (UFC) diversas ações de extensão são desenvolvidas, dentre elas, o Curso de Capacitação de Profissionais da Área de Saúde em Intervenção Precoce que integra o Programa de Intervenção Precoce e Reabilitação do Desenvolvimento na Primeira Infância, vinculado ao Departamento de Saúde Materno-Infantil e ao Núcleo de Tratamento e Estimulação Precoce (NUTEP).

A Extensão é uma via de mão-dupla, onde se assegura à comunidade acadêmica, por 
um lado, a oportunidade de elaboração da práxis de um conhecimento acadêmico, estabelecendo a troca de saberes sistematizados, democratizando o conhecimento acadêmico, por outro lado, pode-se ter a participação efetiva da comunidade na atuação da Universidade.

No contexto extensionista de articulação entre o ensino, pesquisa e comunidade, em outubro de 2013, foi implantado o Teste da Linguinha no Setor de Fonoaudiologia do NUTEP.

O leite materno vem a ser o alimento mais completo para todo recém-nascido (RN), sendo a amamentação de extrema importância para a saúde do RN. Segundo Marchesan, Martinelli e Gusmão (2012, p. 1780) a Organização Mundial de Saúde (OMS) preconiza que a amamentação deve ser a fonte exclusiva de nutrição nos seis primeiros meses de vida. Segundo a OMS a amamentação é um importante auxílio para o desenvolvimento das funções orais (KARKOW et al., 2014, p. 5494), porém é importante ressaltar que podem haver situações que dificultem a amamentação e levem ao desmame precoce.

Por ser a língua um órgão extremamente especializado, participando ativamente das funções orais e possuir em sua face inferior uma membrana mucosa que a conecta ao assoalho da boca, a Lei No 13.002/14 (BRASIL, DOU, 2014), obriga a realização do Teste da Linguinha em todos os hospitais e maternidades, nas crianças nascidas em suas dependências, tendo como principal objetivo a prevenção do desmame precoce.

Composto por tecido conjuntivo fibrodenso e, ocasionalmente, por fibras superiores do músculo genioglosso (NAVARRO e LÓPEZ, 2002 apud MARCHESAN, TEIXEIRA e CATTONI, 2010, p. 196), quando não ocorre a apoptose completa do frênulo lingual, durante o período embrionário, pode haver interferência na livre movimentação da língua (MARTINELLI et al. 2012, p. 138), limitando assim os movimentos deste órgão em diferentes graus, dependendo da fixação do frênulo (MESSNER E LALAKEA, 2002 apud MORISSO, BERWING e SILVA, 2012, p. 203).

Diversos autores classificam o frênulo lingual, quer levando em consideração a fixação do frênulo lingual (Comitê de Motricidade Orofacial da Sociedade Brasileira de Fonoaudiologia - SBFa 2003 apud WITWYTZKYJ, CORDEIRO e COELHO, 2014, p. 537), quer levando em consideração o grau de comprometimento (BHASKAR, 1976; ZEGARELLI, KUTSHER e HYMAN, 1982 apud MORISSO, BERWING e SILVA, 2012, p. 204).

Para Knox (2010 apud MARTINELLI, 2013, p. 19) a alteração do frênulo lingual é uma anomalia oral congênita, ainda não havendo estudos conclusivos sobre sua embriogênese, podendo ser resultante de mutação do gene T-Box, com heranças autossômica dominante e penetrância incompleta, segundo Braybrook et al. (2002), Morita et al. (2004) e Klockars (2007) 
apud Martinelli et al. (2012, p. 5).

Marchesan, Teixeira e Cattoni (2010, p. 196) citam diversos estudos para descrever modificações nos movimentos da língua e dos lábios, a interferência na forma de se alimentar, principalmente na fase da amamentação, o impacto do frênulo alterado à mastigação e deglutição. Citam, também, estudos que relatam o consenso da literatura, afirmando que nem sempre ocorrem alterações de fala relacionadas ao frênulo lingual alterado. Alterações ortodônticas e de praxia oral também são relatados (MORISSO, BERWING e SILVA, 2012, p. 206-207).

No RN, como a sucção durante a amamentação requer uma pressão do mamilo sobre o palato duro com movimentação rítmica da língua (SRINIVASAN et al., 2006 apud MORISSO, BERWING e SILVA, 2012, p. 206), a dificuldade na pega do mamilo, estaria comprometendo esta função. Porém Martinelli (2013, p. 63-64) afirma que esta dificuldade, bem como a dor materna durante a amamentação, não pode servir para o diagnóstico da língua presa. Aqui merece atenção especial para que se previna o desmame precoce e/ou baixo ganho de peso, relatados por Martinelli (2013, p. 16) e Witwytzkyj, Cordeiro e Coelho (2014, p. 537) em diversos estudos.

Em estudo histológico, Martinelli et al. (2014, p. 7) descreveram a presença/ausência de fascículos de fibras musculares; a presença de fibras colágenas em todos os diferentes tipos de frênulos avaliados, com predominância das do tipo I e III, sendo as primeiras, segundo Benjamin e Ralphs (1997 apud MARTINELLI et al., 2014, p. 7) altamente resistentes à tração, interferindo nas funções orofaciais; o entrelaçamento da membrana mucosa com as fibras musculares estriadas esqueléticas, limitando os movimentos da língua, conferindo maior mobilidade às margens laterais da língua do que a parte anterior.

Martinelli et al. (2012, p. 139) menciona que embora Hazelbaker (1993) tenha proposto protocolo para avaliação do frênulo em bebês até o sexto mês de vida, este recebeu críticas de Ricke et al. (2005) por não fazer correlações entre a alteração do frênulo e as dificuldades na amamentação, sendo considerado por Knox (2010) um protocolo complexo e não validado, afirmando que a falta de critérios estabelecidos para a avaliação e classificação do frênulo lingual, tem contribuído para inviabilizar a comparação de resultados entre estudos.

Martinelli et al. (2012, p. 139) propuseram protocolo que faz relação entre a alteração do frênulo lingual às funções de sucção e deglutição, porém “[...] a comparação com um protocolo padrão ouro não poderá ser realizada porque não foram encontrados protocolos validados de avaliação do frênulo lingual para bebês já publicados" (MARTINELLI, 
MARCHESAN e BERRETIN-FELIX, 2013, p. 608), protocolo este que utiliza escores por facilitar a avaliação da gravidade da disfunção, bem como possibilitar a padronização da avaliação e consequentemente favorecer a comparação de estudos de diferentes centros para que seja possível minimizar as controvérsias.

Com os estudos de Martinelli, Marchesan e Berretin-Felix (2013, p. 607) os índices de incidência passaram a ter expressão mais significativa, provavelmente, por incluir aspectos anatomofuncionais além da sucção não nutritiva e nutritiva durante amamentação, diferentemente das metodologias empregadas nos estudos anteriores. Eles evidenciaram relações entre a tendência do posicionamento da língua durante o choro com o tempo entre as mamadas; forma da língua quando elevada com o cansaço para mamar; fixação do frênulo na língua com o movimento de língua na sucção não nutritiva; formato da língua no choro com ritmo de sucção e tempo da pausa; formato da ponta da língua com fenda quando elevada durante o choro e tempo de pausa prolongado.

Para Martinelli, Berretin-Felix e Marchesan (2014, p. 36) na grande maioria das vezes as alterações do frênulo lingual não são diagnosticadas no exame físico do RN, antes da alta da maternidade e dificilmente o diagnóstico seja realizado no primeiro ano de vida, sendo raramente as alterações do frênulo lingual atribuídas às disfunções orais. Porém, segundo Lofredo-Bonatto (2012 apud SÃO PAULO, 2012, p. 106), o pique nas crianças com língua presa, era prática executada por parteiras, no século passado.

Diversas técnicas cirúrgicas são relatadas nos casos de frênulo alterado. Martinelli, Marchesan e Berretin-Felix (2013, p. 608) citam estudos que mencionam a frenotomia, enquanto Knox (2010 apud MARCHESAN, MARTINELLI, GUSMÃO, 2012, p. 410) refere que a frenectomia "[...] é o procedimento mais comum para liberar o frênulo lingual", não havendo indicação cirúrgica o frênulo lingual submerso, por não interferir na amamentação (MARTINELLI, MARCHESAN e BERRETIN-FELIX, 2014, p. 51).

Martinelli et al. (2014, p. 7-8) indicaram a frenectomia na anquiloglossia, baseado nos estudos histológicos, embora diversos autores tenham afirmado existir elasticidade e ruptura natural no frênulo lingual (MARTINELLI et al. 2012, p.2263).

Para Marchesan, Martinelli e Gusmão (2012, p. 412) após a frenectomia ocorre uma melhora, em diferentes graus, na postura de lábios e língua, na mobilidade da língua, nas funções orais, estando esta melhora na dependência do tipo de alteração do frênulo lingual, na idade da criança e nos diferentes procedimentos cirúrgicos realizados.

As controvérsias diagnósticas e de condutas a serem tomadas, segundo Martinelli, 
Marchesan e Berretin-Felix (2014, p. 1202) podem causar prejuízo ao paciente, conferindo um diagnóstico inconclusivo e consequentemente, um tratamento inadequado.

Alves et al. (2014, p. 89) enfatizaram a importância do trabalho interdisciplinar junto ao frênulo lingual alterado para que promova, “[...] a adequação anatomofuncional e a adequação das funções de fala e de alimentação comprometidas”.

Em saúde pública, a Triagem Neonatal $(\mathrm{TN})$ que é o rastreamento na população com idade entre 0 a 30 dias de vida a fim de identificar uma determinada patologia (BRASIL, MANUAL DE NORMAS TÉCNICAS, PNTN, 2002) foi proposta pelo Dr. Robert Guthrie, em 1963 e, desde então, grandes conquistas foram alcançadas no Brasil.

Segundo Pollitt (2006) e Wilcken et al. (2003) apud Leão e Aguiar (2008, S81), embora existam critérios estabelecidos para a triagem neonatal, devido a heterogeneidade das doenças rastreadas e a difícil execução de estudos controlados randomizados, nem sempre se consegue seguir todos os critérios estabelecidos, devido a muitas destas doenças serem raras.

Como a Lei $N^{\circ} 8.080$ de 19 de setembro de 1990, em seu TÍTULO II, Artigo $4^{\circ}, \S 2^{\circ}$ permite que a iniciativa privada participe do SUS, em caráter complementar, (BRASIL, LEI N ${ }^{\circ}$ 8.080, 1990) o NUTEP que é uma instituição de direito privado sem fins lucrativos, constituída sob forma de associação, tendo títulos de utilidade pública municipal, estadual e federal, vem prestando assistência permanente a crianças com risco, transtorno ou desarmonia do desenvolvimento e suas famílias, através do Sistema Único de Saúde (SUS).

\section{DESENVOLVIMENTO}

Com o propósito de apresentar um novo serviço do Setor de Fonoaudiologia do NUTEP, propõe-se, neste estudo, o relato de sua implantação na instituição e a apresentação dos dados coletados desde sua implantação, no sentido de buscar a promoção da saúde, a qualidade de vida, a capacitação profissional dos envolvidos, além de conhecer a rede de assistência às crianças diagnosticadas com frênulo lingual alterado em Fortaleza.

Neste contexto o Setor de Fonoaudiologia do NUTEP iniciou, em outubro de 2013, após treinamento no Teste da Linguinha, ministrado pela fonoaudióloga Roberta Martinelli, o serviço de avaliação do frênulo lingual em bebês. Inicialmente o teste foi destinado ao RN encaminhado da Maternidade Escola Assis Chateaubriand, logo sendo agendada avaliação às crianças assistidas no NUTEP, além das encaminhadas por outras unidades de saúde. 


\section{MÉTODO}

Trata-se de um relato de experiência, descritivo, realizado de outubro de 2013 a julho de 2015, no Setor de Fonoaudiologia do NUTEP.

Realizou-se uma revisão da literatura com a finalidade de aprofundar o conhecimento do assunto investigado. A questão norteadora deste estudo foi a importância do Teste da Linguinha na promoção da saúde e sua importância na inclusão da triagem neonatal.

A princípio buscou-se artigos de setembro de 2014 a julho de 2015, consultando as bases de dados da Biblioteca Virtual de Saúde, do Bando de Dados Bibliográficos da Universidade de São Paulo, do Scientific Eletronic Library Online, do Literatura Latino-Americana e do Caribe em Ciências da Saúde, do National Library of Medicine, da Biblioteca Regional de Medicina e do Portal da Saúde do Ministério da Saúde (MS).

Foram incluídas publicações que relatam aspectos do frênulo lingual e sua correlação com as alterações orofaciais, intervenção cirúrgica, avaliação do frênulo lingual, triagem neonatal, além de ações, serviços e programas desenvolvidos pelo MS, usando os seguintes termos em português: freio lingual, protocolo clínico, aleitamento materno e triagem neonatal; e dos seguintes termos em inglês: lingual frenum, clinical protocols, breastfeeding and neonatal screening; publicados nos últimos cinco anos, com exceção de algumas Portarias do MS e do Manual de Normas Técnicas e Rotinas Operacionais do Programa Nacional de Triagem Neonatal do MS.

Nos resultados foi descrita a implantação do Teste da Linguinha no Setor de Fonoaudiologia do NUTEP, analisando os procedimentos realizados, caracterizando as crianças avaliadas.

O protocolo foi realizado de segunda a sexta, no período diurno, sendo solicitado o jejum durante 02 horas, além de dar orientações quanto à posição mais indicada para amamentação e quanto à pega correta.

Foram incluídos neste estudo crianças assistidas no NUTEP e encaminhadas para avaliação do frênulo lingual e as referenciadas pelos diversos Estabelecimentos de Saúde da Rede Municipal de Fortaleza. As crianças foram avaliadas por fonoaudiólogas treinadas, utilizando-se o protocolo de frênulo lingual proposto por Martinelli (MARTINELLI, MARCHESAN e BIRRETIN-FELIX, 2013, p. 603-606), tendo a participação de uma extensionista de fonoaudiologia do Curso de Capacitação de Profissionais da Área de Saúde em Intervenção Precoce, do Programa de Intervenção Precoce e Reabilitação do Desenvolvimento na Primeira Infância, do Departamento de Saúde Materno-Infantil e do NUTEP. 
O Teste é composto pela história clínica e exame clínico, sendo este último subdividido em avaliação anatomofuncional e avaliação da sucção não nutritiva e nutritiva.

Foram atribuídos escores para cada item, variando de 0 a 3, sendo conferidos escores parciais, para os casos nos quais não foi possível aplicar o protocolo completo e, escore total, para os casos nos quais foi possível aplicar o protocolo completo. Nos primeiros, para as crianças que já haviam desmamado ou mamavam, mas as mães não puderam comparecer e, nos últimos, para as crianças que se pode avaliar a sucção nutritiva na amamentação.

Inicialmente foram realizados questionamentos sobre a dados pessoais, antecedentes familiares de frênulo lingual alterado, problemas de saúde e amamentação, sendo atribuído pontuação mínima de 4 na história clínica para indicar a interferência do frênulo lingual nos movimentos da língua.

A seguir iniciou-se o exame clínico, mais especificamente a avaliação anatomofuncional, itens de 1 a 3, atribuindo pontuação mínina de 4 para indicar a interferência do frênulo lingual nos movimentos da língua.

Dando prosseguimento à avaliação anatomofuncional, foi realizada elevação das margens laterais da língua, com os dedos indicadores enluvados, sendo realizada manobra para visualização do frênulo lingual. E finalizando a avaliação anatomofuncional, item 4, atribuindo pontuação mínima de 3 para indicar a interferência do frênulo lingual nos movimentos da língua. Importante ressaltar que quando o escore parcial da avaliação anatofuncional pontuou entre 5 e 6 foi considerado escore duvidoso.

Para concluir o Teste, foi realizada a avaliação da sucção não nutritiva com dedo enluvado do examinador introduzido na boca da criança para, a seguir ser realizada a avaliação da sucção nutritiva, durante amamentação, sendo atribuída pontuação mínima de 2 para indicar a interferência do frênulo lingual nos movimentos da língua.

Nos casos em que todos os itens do protocolo foram aplicados pode-se considerar a interferência do frênulo nos movimentos da língua através do escore total, obtido pela somatória de todos os escores parciais com pontuação mínima de 13.

Diante de situações nas quais não foi possível obter dados acerca da história clínica pode-se considerar a interferência do frênulo nos movimentos da língua com pontuação mínima de 9 .

\section{RESULTADOS}

No período de realização deste estudo, o Município de Fortaleza, segundo Cadastro 
Nacional de Estabelecimento de Saúde, dispunha de 25 estabelecimentos com leitos de obstetrícia clínica e/ou cirúrgica credenciadas ao SUS e 12 não credenciados (BRASIL, CNES, 2015), sendo que apenas um destes estabelecimentos referiu crianças ao NUTEP.

Foram avaliadas 286 crianças, sendo que 145 (51\%) já estavam inseridas no programa assistencial da instituição, enquanto 141 (49\%) foram referidas por demanda espontânea, por profissionais de saúde ou por outros estabelecimentos de saúde das diversas Secretarias Executivas Regionais de Fortaleza.

Das crianças avaliadas, 269 (94\%) apresentaram idade entre zero e trinta e seis meses, enquanto 17 (6\%) apresentaram idade acima de trinta e seis meses e um dia. No que se refere ao sexo, 170 (59\%) era do sexo masculino e $116(41 \%)$ do sexo feminino.

O frênulo lingual foi considerado normal em 76 (27\%) crianças, por obter-se escore não indicativo de interferência do frênulo lingual nos movimentos da língua. Foi considerado alterado em 175 (61\%) crianças, por obter-se escore indicativo de interferência do frênulo lingual nos movimentos da língua. E duvidoso em 35 (12\%).

As 76 crianças com frênulo lingual normal receberam alta. As 175 crianças com frênulo alterado foram encaminhadas, com relatório do protocolo, às Unidades Básicas de Saúde correspondente aos seus respectivos bairros, a fim de agendarem consulta com pediatra que por sua vez as regulariam ao serviço disponível para cirurgia do frênulo lingual. Foi solicitado que estas crianças retornassem ao serviço do NUTEP após a cirurgia, a fim de orientar a família para realizar a manobra de elevação da língua durante o período pós-cirúrgico para evitar aderências, enquanto que nas 35 (12\%) crianças com escores duvidosos foi agendado reteste, que deveria ser realizado no prazo de 30 dias.

Das 175 crianças nas quais o frênulo lingual foi considerado alterado, 12 (7\%) realizaram a cirurgia do frênulo lingual, sendo a frenectomia realizada em apenas 1 e a frenotomia em 11. As 163 (93\%) crianças restantes encontram-se em lista de espera, aguardando o procedimento cirúrgico.

\section{DISCUSSÃO}

De acordo com o Art. $2^{\circ}$ da Lei $N^{\circ} 13.002 / 14$ (BRASIL, 2014), desde dezembro de 2014, todas as crianças deveriam receber alta após o parto com o Teste da Linguinha realizado. Sabendo que incidência de anquiloglossia varia, segundo diversos autores, de 0,88\% a 12,8\% (MARTINELLI et al, 2012, p. 139) e que em nosso município nasceram 47.743 bebês em 2013, grande quantidade de RN poderá apresentar língua presa.

Sabendo que a Sala de Apoio à Gestão Estratégica (BRASIL, SAGE, 2015) do MS tem 
como um dos objetivos para o milênio a redução da mortalidade infantil e por ser o aleitamento materno exclusivo uma política governamental para este fim e que o desmame precoce devido à língua presa tem incidência elevada, ações que tenham como objetivo sanar barreiras ao aleitamento materno devem ser disseminadas.

Sendo assim, a inclusão do Teste da Linguinha no PNTN, a incorporação do mesmo à Tabela do SUS, bem como a inclusão do registro do Teste na Caderneta de Saúde da Criança, além da participação do Agente Comunitário de Saúde poderiam facilitar a assistência às crianças com língua presa, visto que embora a frenectomia esteja incluída na Tabela de Procedimentos, Medicamentos e Órteses, Próteses e Materiais Especiais (BRASIL, SIGTAP, 2015), pode-se constatar uma enorme lista de espera para este procedimento, como referiram as mães das crianças diagnosticadas com língua presa, neste estudo.

\section{CONCLUSÃO}

Observou-se a importância da implantação do Teste da Linguinha na Instituição, enquanto atividade extensionista promotora de saúde e de qualidade de vida das crianças avaliadas, por possibilitar a intervenção precoce junto às alterações do frênulo lingual, prevenindo o desmame precoce e o baixo ganho de peso, sendo de fundamental importância a participação de algumas unidade de saúde na realização da frenotomia, tendo a criança menor de 3 anos maior acesso ao procedimento cirúrgico, graças as ações da Política Nacional de Saúde Bucal - Programa Brasil Sorridente (BRASIL, PNSB, 2013), sendo de extrema importância que os cuidados prestados ao RN diagnosticado com língua presa sejam ampliados, que estudos justifiquem a importância epidemiológica e a avaliação do custo-benefício para o tratamento precoce da alteração do frênulo lingual, que critérios e normas técnicas para esta triagem sejam estabelecidos e que o Teste da Linguinha passe a ser rotina em todos as maternidades e hospitais. Para tanto, faz-se necessário à criação de uma rede de atenção para este fim, visto que estas ações intersetoriais, em parceria com organizações governamentais e a sociedade civil, poderão impactar significativamente no desenvolvimento na primeiríssima infância.

\section{REFERÊNCIAS}

ALVES, Isabela Luisa Fiuza et al. Intervenção interdisciplinar no frênulo lingual: um caso de sucesso. In: Jornada Fonoaudiológica de Bauru "Profa. Dra. Deborah Viviane Ferrar", 21. 2014: Bauru, SP: 2014. Anais... Bauru, SP: FOB-USP, p. 89, 2014. Disponível em: http://www.cofab.fob.usp.br/wp-content/uploads/Anais-2014.pdf. Acesso em: 01 mai. 2015. 
BRASIL. Presidência da República. Casa Civil. Subchefia para Assuntos Jurídicos. Lei No 8.080, de 19 de setembro de 1990. Dispõe sobre as condições para a promoção, proteção e recuperação da saúde, a organização e o funcionamento dos serviços correspondentes e dá outras providências. Disponível em: http://www.planalto.gov.br/ccivil_03/Leis/L8080.htm. Acesso em: 31 jan. 2015.

Ministério da Saúde. Secretaria de Assistência à Saúde. Coordenação-Geral de Atenção Especializada. Manual de Normas Técnicas e Rotinas Operacionais do Programa Nacional de Triagem Neonatal/Ministério da Saúde, Secretaria de Assistência à Saúde, Coordenação Geral de Atenção Especializada. - Brasília: Ministério da Saúde, 2002. 90 p.: il. - (Série A. Normas e Manuais Técnicos). Disponível em: http://bvsms.saude.gov.br/bvs/publicacoes/triagem_neonatal.pdf. Acesso: em 2 nov. 2014.

Presidência da República. Casa Civil. Subchefia para Assuntos Jurídicos. Lei No 13.002, de 20 de junho de 2014. Obriga a realização do Protocolo de avaliação do Frênulo da Língua com Escores para Bebê sem todos os hospitais e maternidades, nas crianças nascidas em suas dependências, em todos os hospitais e maternidades, nas crianças nascidas em suas dependências. Brasília. Diário Oficial da União, Brasília, DF., 23 jun. 2014. Seção 1. Edição Extra. p. 4. Disponível em: http://www2.camara.leg.br/legin/fed/lei/2014/lei-13002-20-junho2014-778947-publicacaooriginal-144433-pl.html. Acesso: em 28 out. 2014.

Ministério da Saúde. Secretaria de Atenção à Saúde. Cadastro de Estabelecimento de Saúde. 2015. Disponível em: http://www.scielo.br/pdf/rcefac/v16n4/1982-0216-rcefac-164-1202.pdf. Acesso em: 19 jan. 2015.

Ministério da Saúde. Sistema de Gerenciamento da Tabela Unificada de Procedimentos, Medicamentos, Órteses, Próteses e Matérias Especiais do Sistema Único de Saúde. Procedimento: frenectomia. Disponível em: http://sigtap.datasus.gov.br/tabelaunificada/app/sec/procedimento/exibir/0401010082/06/2015. Acesso em: 22 mar. 2015.

. Ministério da Saúde. Secretaria de Atenção à Saúde. Departamento de Atenção Básica. Coordenação-Geral de Saúde Bucal. Política Nacional de Saúde Bucal - BRASIL SORRIDENTE. Passo a passo das ações do Brasil Sorridente. Brasília, DF., 2013. Disponível em: http://189.28.128.100/dab/docs/portaldab/documentos/passo_a_passo_ceo.pdf. Acesso em: 30 mai. 2015.

Ministério da Saúde. Sala de Apoio à Gestão Estratégica. Brasília, DF., Disponível em: http://189.28.128.178/sage/. Acesso em: 30 abr. 2015.

\section{FORUM DE PRÓ-REITORES DE EXTENSÃO DAS UNIVERSIDADES PÚBLICAS} BRASILEIRAS. Indissociabilidade ensino-pesquisa-extensão e a flexibilidade curricular: uma visão de extensão. Porto Alegre: UFRGS; Brasília: MEC/SESu, 2006. Disponível em: https://www.unifal-

mg.edu.br/extensao/files/file/colecao_extensao_univeristaria/colecao_extensao_universitaria_ 4_indissociabilidade.pdf. Acesso em: 06 mai. 2017.

KARKOW, Isabella Karina et al. Aleitamento materno e sua relação com o frênulo lingual. In: CONGRESSO BRASILEIRO DE FONOAUDIOLOGIA, 22., 2014, Joinvile. SC: 
2014. Anais... Joinvile: Sociedade Brasileira de Fonoaudiologia. p. 5494. Disponível em: http://sbfa.org.br/portal/anais2014/trabalhos_exp_select.php?tp=P\&id_artigo=5494. Acesso em: 20 jul. 2015.

LEÃO, Letícia Lima; AGUIAR, Marcos José Burle de. Triagem neonatal: o que os pediatras deveriam saber. J. Pediatr. (Rio J.), Porto Alegre, v. 84, n. 4, supl. p. S80-S90, ago. 2008. Disponível em: http://www.scielo.br/scielo.php?script=sci_arttext\&pid=S0021$75572008000500012 \& \operatorname{lng}=e n \& n r m=i$ so. Acesso em: 18 ago. 2015. http://dx.doi.org/10.1590/S0021-75572008000500012.

MARCHESAN, Irene Queiroz; TEIXEIRA, Adriana Nascimento; CATTONI, Débora Martins. Correlações entre diferentes frênulos linguais e alteração na fala. Distúrb. Comum. v. 22, n. 3, p. 195-200. dez. 2010. Disponível em:

http://revistas.pucsp.br/index.php/dic/article/viewFile/7312/5309. Acesso em: 02 dez. 2014.

MARCHESAN, Irene Queiroz; MARTINELLI, Roberta Lopes de Castro; GUSMÃO, Reinaldo Jordão. Frenotomia lingual: evitando o desmame precoce. In: CONGRESSO BRASILEIRO DE FONOAUDIOLOGIA, 20., 2012, Brasília. DF: 2012. Anais... Brasília: Sociedade Brasileira de Fonoaudiologia. p. 1780. Disponível em: http://www.sbfa.org.br/portal/anais2012/trabalhos_select.php?id_artigo=1780\&tt=SESS\%C3 O\%20DE\%20CONCORRENTES\%20A\%20PR\%CAMIO. Acesso em: 21 jul. 2015.

Frênulo lingual: modificações após frenectomia. J. Soc. Bras. Fonoaudiol., São Paulo, v. 24, n 4, p. 409-412, 2013. Disponível em: http://www.scielo.br/scielo.php?script=sci_arttext\&pid=S217964912012000400020\&lng=en\&nrm=iso. Acessado em: 21 jul. 2015. http://dx.doi.org/10.1590/S2179-64912012000400020.

MARTINELLI, Roberta Lopes de Castro. Relação entre as características anatômicas do frênulo lingual e as funções de sucção e deglutição em bebês. 2013. 98 p. Dissertação (Mestrado Processos e Distúrbios da Comunicação) - Faculdade de Odontologia de Bauru, Universidade de São Paulo, Bauru, 2013. Disponível em:

file://C:/Users/User/Downloads/RobertaLopesdeCastroMartinelli_Rev.pdf. Acesso em: 01 set. 2014.

Frênulo lingual: o diagnóstico precoce é realizado no Brasil? In: ENCONTRO BRASILEIRO DE MOTRICIDADE OROFACIAL, 7., 2014. São Paulo. SP. Anais... São Paulo: Associação Brasileira de Motricidade Orofacial, 2014. p. 36. Disponível em: http://www.abramofono.com.br/wp-content/uploads/2014/05/ANAIS-DO-VII-ENCONTROBRASILEIRO-DE-MOTRICIDADE-OROFACIAL.pdf. Acesso em: 15 nov. 2014.

MARTINELLI, Roberta Lopes de Castro; MARCHESAN, Irene Queiroz; BERRETINFELIX, Giédre. Protocolo de avaliação do frênulo lingual para bebês: relação entre aspectos anatômicos e funcionais. Rev. CEFAC, São Paulo, v. 15, n. 3, p. 599-610, mai./jun. 2013. Disponível em: http://www.scielo.br/pdf/rcefac/v15n3/162-11.pdf. Acesso em: 31 out. 2014.

O frênulo lingual submerso interfere na amamentação? In: ENCONTRO

BRASILEIRO DE MOTRICIDADE OROFACIAL, 7., 2014, São Paulo. Anais... São Paulo: Associação Brasileira de Motricidade Orofacial, 2014. p. 51. Disponível em: 
http://www.abramofono.com.br/wp-content/uploads/2014/05/ANAIS-DO-VII-ENCONTROBRASILEIRO-DE-MOTRICIDADE-OROFACIAL.pdf. Acesso em: 01 abr. 2015.

Estudo longitudinal das características anatômicas do frênulo comparado com afirmações da literatura. Rev. CEFAC, São Paulo, v. 16, n. 4, p. 1202-1207, jul-ago, 2014. Disponível em: http://www.scielo.br/pdf/rcefac/v16n4/1982-0216-rcefac-16-4-1202.pdf. Acesso em: 14 dez. 2014.

MARTINELLI, Roberta Lopes de Castro et al. Protocolo de avaliação do frênulo da língua em bebês. Rev. CEFAC [online]. 2012, São Paulo, v. 14, n. 1, p. 138-145, jan./fev. 2012. Disponível em: http://www.scielo.br/scielo.php?script=sci_arttext\&pid=S151618462012000100016\&lng=pt\&nrm=iso\&tlng=en. Acesso em: 03 fev. 2015. http://dx.doi.org/10.1590/S1516-18462012000100016.

Características histológicas do frênulo lingual em humanos. In: CONGRESSO BRASILEIRO DE FONOAUDIOLOGIA, 20., 2012, Brasília, DF, Anais... Brasília: Sociedade Brasileira de Fonoaudiologia, 2012. p. 2263. Disponível em: http://www.sbfa.org.br/portal/anais2012/trabalhos_exp_select.php?tp=P\&id_artigo=2263. Acesso em: 22 jan. 2015.

Histological characteristics of altered human lingual frenulum. Internatiocal Journal of Pediatrics and Child Healt, [sl], v. 2, n. 1, p. 5-9, aug. 2014. Disponível em: http://savvysciencepublisher.com/international-journal-pediatrics-child-health-voume2issue1/. Acesso em: 03 fev. 2015.

MORISSO, Marcela Forgiarini; BERWIG, Luana Cristina; SILVA, Ana Maria Toniolo da. Anquiloglossia: ocorrência de alterações do sistema estomatognático. RGO, Porto Alegre, v. 60, n. 2, p. 203-208, abr./jun., 2012. Disponível em: http://www.revistargo.com.br/viewarticle.php?id=1926. Acesso em: 22 mar. 2015.

SÃO PAULO, Governo do Estado de São Paulo. Casa Civil. Câmara Municipal de São Paulo. Gabinete do Presidente. Projeto de Lei No 01-00511 de 11 de dezembro de 2012. Torna obrigatório à realização do "teste da linguinha" dos recém-nascidos e bebês no Município de São Paulo e dá outras providencias. Diário Oficial do Estado de São Paulo, São Paulo, 12 dez. 2012. p. 106. Disponível em: http://www.jusbrasil.com.br/diarios/44175161/dosp-cidade12-12-2012-pg-106/pdfView. Acesso em: 01 dez. 2014.

WITWYTZKYJ, Lígia Patron; CORDEIRO, Mariane Cristina; COELHO, Tânia Terezinha Tozi. Análise clínica das propostas de classificação do frênulo da língua por índice e porcentagem. Rev. CEFAC, São Paulo, v. 16, n. 2, p. 537-545, mar./abr. 2014. Disponível em: http://www.scielo.br/scielo.php?script=sci_arttext\&pid=S151618462014000200537\&lng=pt\&nrm=iso. Acesso em: 02 abr. 2015. http://dx.doi.org/10.1590/1982-0216201421112. 